\title{
Numerical Heat Transfer Comparison Study of Hybrid and Non- hybrid Ground Source Heat Pump Systems
}

\author{
Nikola Kuzmic, Ying Lam E. Law, Seth B. Dworkin* \\ Department of Mechanical and Industrial Engineering, Ryerson University \\ 350 Victoria St., Toronto, ON, Canada, M5B 2K3
}

\begin{abstract}
Ground Source Heat Pump (GSHP) systems, if improperly designed may lead to overheating or overcooling of the ground. Good designs ensure properly balanced energy storage through adequately sizing ground-loops. Hybrid systems combine conventional Heating, Ventilating, and Air Conditioning (HVAC) with GSHPs in order to significantly reduce the high installation costs of GSHPs. The hybrid systems are designed in such a way that GSHPs provide the base building energy demands while the conventional HVAC is used only during the peak hours. In general, all buildings can be divided into two main categories: cooling dominant and heating dominant. If a building is cooling dominant, ground temperature increases with time and in heating dominant cases it decreases. A severe ground temperature increase/decrease is referred to as 'ground fouling' because it can render the GSHP inoperable, as temperature differences are required to maintain controlled heat flow. This paper compares long-term operation of hybrid and nonhybrid GSHP systems in order to investigate the effectiveness of hybridization at alleviating 'ground fouling'. A homespun 2D finite-volume model is proposed to study heat transfer in ground coupled heat pump systems and is verified against an analytical solution as well as experimental data. Through simulation of different building types, it is demonstrated that hybridization has potential to reduce 'ground fouling' but only in limited cases for which a large portion of the energy demands is being met by the conventional HVAC.
\end{abstract}

*Corresponding Author seth.dworkin@,ryerson.ca 


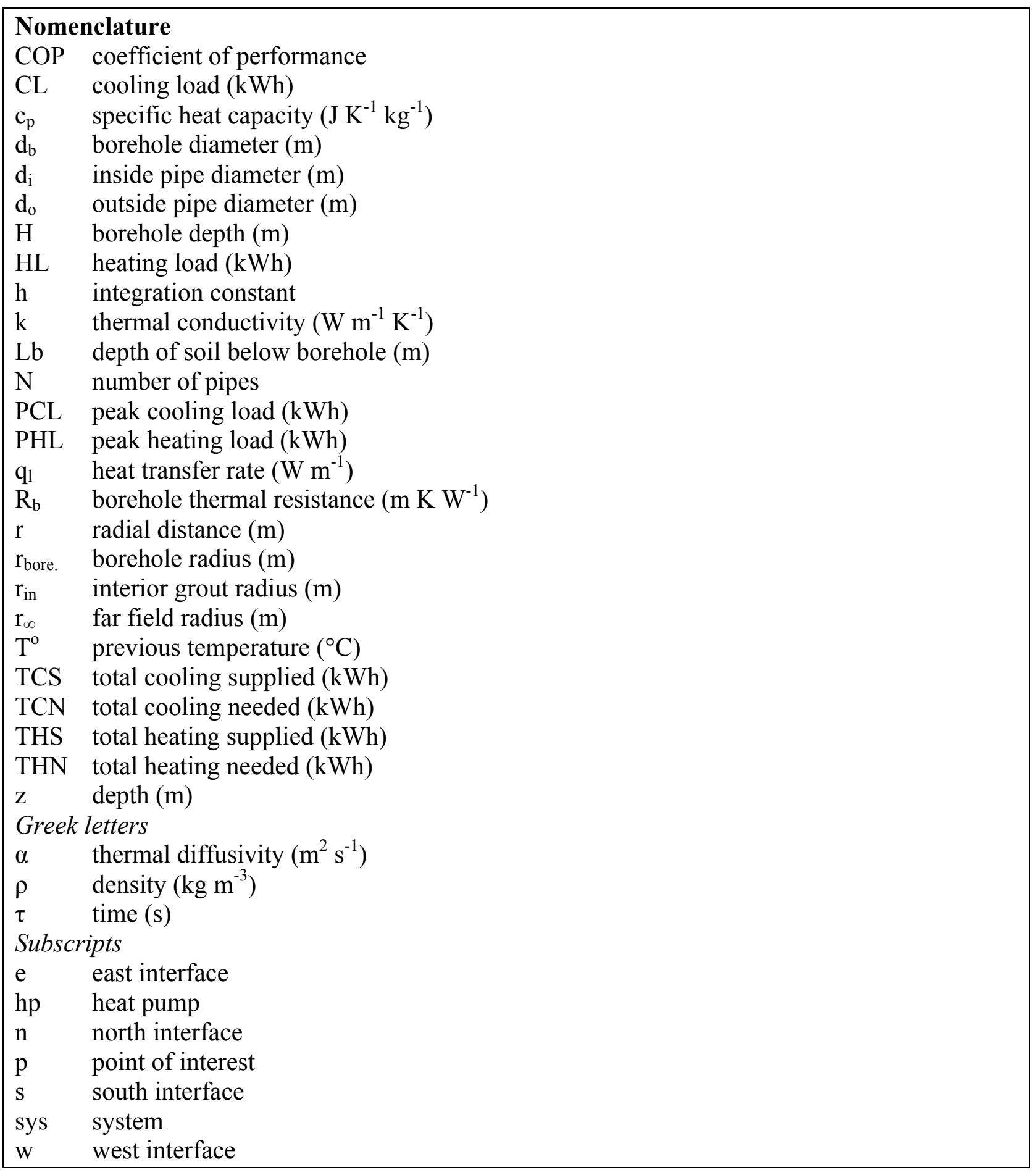




\section{Introduction}

Geo-exchange is an emerging technology which is gaining popularity as an environmentally friendly alternative to conventional Heating, Ventilating, and Air Conditioning (HVAC) systems. Through extracting ground heat in the winter, Ground Source Heat Pump (GSHP) systems heat buildings and reduce natural gas consumption. To cool dwellings in the summer, the systems exploit the ground's ability to remain cool and absorb heat and consequently reduce strain on the electrical grid. It has been reported that replacing $16 \%$ of conventional heating systems in Canada by geo-exchange systems would result in a $\mathrm{CO}_{2}$ reduction equivalent to removing 895,845 cars from the roads [1]. Presently, the lack of understanding of heat transfer in ground coupled heat pump systems is one of the factors that prevents the industry from expanding and being competitive in the marketplace.

Two main categories into which buildings can be divided are: cooling dominant and heating dominant. Cooling dominant type implies that the building requires more cooling than heating. The effect of such imbalanced energy demand for cooling would result in ground temperature increasing over long periods of time, since more heat would be injected into the ground than extracted. In heating dominant cases, ground temperature would decrease as more heat would be extracted from the ground than injected. When the imbalance is severe, a general term used to describe such ground overheating/overcooling is called 'ground fouling'. As GSHPs relay solely on the ground to either store or provide heat via a ground-loop, a fouled ground ultimately renders the system inefficient or even inoperable, and induces additional costs to the owner. The solution to the problem is complex, but a properly designed system which operates without overheating or overcooling the ground, can be achieved in many cases.

Hybridization of GSHPs implies that a GSHP is installed together with an auxiliary conventional HVAC system. Hybrid GSHP systems are most often designed in such a way that the GSHP provides the base building loads and the auxiliary HVAC system is only used during the peak demands. Hybridization will normally help balance ground heat input/output since GSHPs can utilize the auxiliary system to provide part of the peak loads, whether they are cooling dominant or heating dominant, and not relay on the ground to store/provide all of the heat. 
Due to high initial costs associated with installation of GSHPs, Alavy et al. [2] have considered hybridizing systems to make them more affordable. In their study they have shown that reduction in costs associated with hybrid systems are considerable while the GSHP component still remains capable of delivering a high percentage of the total energy demands. Their approach to determining the most economical shave factor is to calculate the required borehole length corresponding to continuously varying shave factors between zero and unity and choose the one which minimizes the total costs which include installation costs and net present value of annual operating costs of the GSHP and conventional systems. The present paper utilizes their methodology in determining the shave factors and builds upon their work as it explores an additional benefit that may be associated with hybrid GSHP systems, namely the potential reduction in the risk of ground fouling.

Kurevija et al. [3] were also motivated by the problem of ground fouling and studied the effect of spacing between adjacent boreholes on the required borehole length using the ASHRAE/Kavanaugh (A/K) and Lund/Eskilson (L/E) models. They examined thermal interference in $7 \times 6$ and $21 \times 2$ borehole arrays. Their findings have shown that for a $7 \times 6$ array with borehole spacing of $4 \mathrm{~m}$, the borehole depth required to provide adequate space conditioning capacity was found to be either $8.2 \%$ or $14.9 \%$ larger than the required depth in the $21 \times 2$ arrangement, according to the $\mathrm{A} / \mathrm{K}$ and L/E models, respectively. Their work is helpful to GSHP designers since it demonstrates the effects of thermal interference. The focus of our work is to further assist designers through exploring the benefits in terms of energy balance improvement associated with hybridization of GSHP systems.

Koohi-Fayegh et al. [4] used a semi-analytical model to examine theoretical performance of GSHP systems in relation to thermal interference of neighbouring boreholes. They were actually interested in quantifying the effects of fouling on the system performance in terms of reversible Coefficient of Performance $\left(\mathrm{COP}_{\text {rev }}\right)$. In order to model heat transfer outside the borehole, they used an analytical finite line-source solution presented by Zeng et al. [6] and coupled it to another semi-analytical solution also presented by Zeng et al. [7] to determine inlet and outlet fluid temperature inside the borehole. The outside and inside models were coupled through two parameters: borehole wall temperature and borehole heat flow. Their study demonstrated that GSHPs with boreholes installed relatively close to each other will not experience $\mathrm{COP}_{\text {rev }}$ drop of 
more than $10 \%$ as the result of thermal interaction of two neighbouring boreholes. The present study is related to their work as it aims to improve operation of GSHPs over long periods of time through ground heat transfer analysis as well. The approach taken in the current work is different from theirs as heat transfer analysis is purely numerical and not semi-analytical. Our work provides designers with information on how hybridization of GSHPs influences temperature increase in the ground, as opposed to investigating the effects of thermal interference.

Salimshirazi [5] presented a discretized 2D finite-volume model and verified it against their own experimental data. The focus of their research was centered on accurately modeling heat transfer in vertical ground heat exchangers utilizing a cylindrical coordinate system and finite line-source solution for inside and outside borehole regions, respectively. They published a fully discretized finite-volume 2D scheme to represent the grout domain. In verifying their model against the analytical finite line-source solution, there were five boundary conditions applied. At the top, farfield, and bottom boundaries, constant temperature boundary conditions of $0^{\circ} \mathrm{C}$ were applied as this was the initial domain temperature. Within the borehole depth, a constant heat flux boundary condition was applied at the interior surface. Lastly, at the interior surface of the bottom disk, below the borehole, an adiabatic boundary condition was applied. In order to be more accurate, our model moved the interior radius of the bottom disk from being right underneath the grout cylinder, infinitesimally close to the centerline. In fact, this was the main difference between our and their model. Salimshirazi managed to get good agreement between experimental and numerical results and concluded that neglecting grout and fluid thermal capacity leads to a maximum error of $4.63 \%$ underestimation in annual Coefficient of Performance (COP) regardless of the u-tube configuration in a GSHP system.

In order to properly determine borehole thermal resistance, fluid, pipe and grout resistances need to be accounted for. Go et al. [8] reviewed various methods of estimating thermal resistance of a borehole where they cited the method proposed by Shonder and Beck [9]. In, Shonder and Beck [9], they multiply the radius of the u-tube pipe by $\sqrt{2}$ to get the equivalent radius which ensures that the cross-sectional area of the equivalent cylinder is the same as that of two u-tubes. Their methodology is further discussed in section 2.1 of this paper as their approach of determining borehole resistance was used in the current work. 
Beier et al. [10] performed an experiment where a single borehole was subject to a constant and an interrupted heat input test. In order to simulate operation of a vertical u-tube ground heat exchanger, a borehole of $18 \mathrm{~m}$ was centered horizontally along the length of the box. The circulating u-tube water was heated with two electric heating elements with $1056 \mathrm{~W}$ injected constantly. In the constant input test, water was continually heated for 52 hours while in the interrupted heat input test there was an interruption of heat input of 2 hours. The experimental data that they published was used to verify the present numerical model.

Significant research has been performed in optimization of GSHP design through heat transfer analysis. Bayer et al. [11] proposed a mathematical procedure for optimization of borehole fields. Retkowski et al. evaluated the best heat extraction strategies for GSHPs [12] and proposed a new bi-criteria mixed-integer nonlinear program (MINLP) for an optimal peak load design [13]. Shang et al. [14] studied the intermittent operation of GSHPs and the influence of various factors on system performance. Esen et al. [15] studied the performance of horizontal and vertical GSHPs in terms of system $\mathrm{COP}_{\text {sys }}$ and heat pump $\mathrm{COP}_{\mathrm{hp}}$. Balbay et al. [16] proposed a threedimensional finite element model to simulate temperature distribution in pavement and bridge slabs. In addition, possible applications of GSHPs for snow melting [17] and heating greenhouses [18] have been investigated.

The aim of this paper is to compare ground fouling in hybrid and non-hybrid systems, possessing different degrees of hybridization, to assess whether hybridization is a design solution which ensures proper long term operation of GSHP systems. This will be accomplished through monitoring the temperature rise in hybrid and non-hybrid system scenarios. The novel contribution of this paper is that it combines heat transfer modelling with optimal hybridization techniques to quantify the benefits of hybridization in terms of ground fouling reduction. The portion of the peak load which a GSHP is capable of supplying is termed as a shave factor. For example, a shave factor of 0.6 implies that the geo-exchange system can meet at most $60 \%$ of the peak load, with the balance being met by an auxiliary system. Hence, twelve different buildings will be analyzed in order to obtain different shave factors. Analysis of different shave factors will give insight into how much hybridization is necessary for hybrid systems to become distinguishable from non-hybrid systems in terms of reduced ground fouling. A homespun 2D numerical model consisting of a grout and soil layer will be proposed in section 2.1. This model 
can be applied in predicting long-term temperature distributions in single vertical u-tube heat exchanger ground domains for both hybrid and non-hybrid systems. Hence, it is useful in predicting the temperature rise and ultimately allows fouling comparison to be made between hybrid and non-hybrid GSHP systems. Then the 2D model will be validated against the analytical finite line-source solution and experimental data provided in [10] in sections 2.2 and 2.3 , respectively. In section 2.4 , an algorithm which is capable of transforming building loads into temperature boundary conditions will be presented as a means of obtaining boundary conditions for the 2D model. Finally, a twenty-year ground temperature profiles will be shown and discussed for the various buildings in section 3. A twenty-year period was chosen for the analysis since it is a typically expected lifetime of a GSHP before significant maintenance is required. The point in the ground that was chosen as capable of providing insight into ground temperature response was $5 \mathrm{~m}$ away from the borehole and $75 \mathrm{~m}$ below the surface.

\section{Model Formulation}

\subsection{Numerical 2D finite-volume model}

In order to build a 2D finite-volume model in cylindrical coordinates it is practical to determine equivalent $\mathrm{u}$-tube geometry as illustrated in Figure 1. The diagram on the left in Figure 1 illustrates the physical configuration of the actual u-tube geometries. In vertical heat exchangers a u-tube made out of high density polyethylene is buried into grout. The diameter of the grout is termed as that of the borehole region. The grout inside the borehole is surrounded by soil as

illustrated in Figure 1. Through calculating total thermal borehole resistance with Equation (1) it becomes possible to transform complex u-tube geometry consisting of fluid, pipe and grout into a single grout layer $[8,9]$ :

$$
R_{b}=R_{\text {grout }}+R_{\text {fluid }}+R_{\text {pipe }}
$$

where,

$$
\begin{gathered}
R_{\text {grout }}=\frac{1}{2 \pi \cdot k_{\text {grout }}} \ln \frac{d_{b}}{\sqrt{N} d_{o}} \\
R_{\text {fluid }}=0.5 \cdot \frac{1}{\pi d_{i} h_{i}}, \text { where } h_{i}=\frac{0.023 \operatorname{Re}^{0.8} \operatorname{Pr}^{n} k_{\text {fluid }}}{d_{i}}
\end{gathered}
$$




$$
R_{\text {pipe }}=0.5 \cdot \frac{\ln \left(d_{o} / d_{i}\right)}{2 \pi k_{\text {pipe }}}
$$

where $k_{\text {grout }}$ is thermal conductivity of grout, $d_{b}$ is the borehole diameter, $N$ is number of pipes in the borehole, $d_{o}$ is the outside pipe diameter, $d_{i}$ is the inside pipe diameter, $h_{i}$ is the internal pipe film coefficient, $n$ is 0.4 for heating and 0.3 for cooling, $k_{\text {fluid }}$ is thermal conductivity of circulating fluid, and $k_{\text {pipe }}$ is thermal conductivity of the pipe.

Equation (1) states that the borehole resistance consists of the resistance associated with the fluid, pipe and grout. Equations (2-4) are commonly used formulations to evaluate grout, fluid and pipe thermal resistances. Equation (2) transforms two u-tube pipes into a single pipe and takes into account the effect of thermal resistance associated with u-tube pipe separation through the thickness of the grout layer.

Setting borehole diameter $\left(d_{b}\right)$ to its known value allows for the interior equivalent diameter to be readily determined with Equation (5):

$$
\mathrm{D}_{\mathrm{eq}}=\frac{d_{b}}{\mathrm{e}^{\mathrm{R}_{\mathrm{b}} \cdot 2 \cdot \pi \cdot \mathrm{kgrout}}}
$$

where $d_{b}$ is the borehole diameter, and $\mathrm{R}_{\mathrm{b}}$ is the borehole resistance.

Equation (5) is very useful as it allows the actual vertical heat exchangers, which in reality have the circulating fluid, u-tubes and grout, to be modelled as a single cylinder of grout, thus permitting axisymmetric modelling. Knowing the inside and outside radii of the grout for the equivalent geometry enables effective approximation of modelling heat transfer in single u-tube boreholes. 

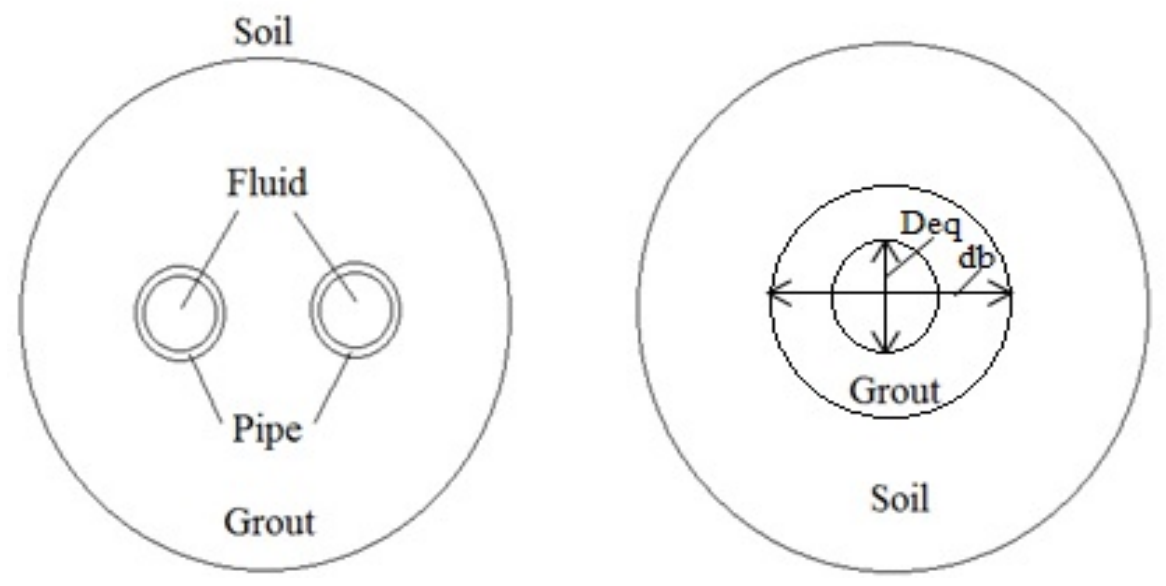

Figure 1. Graphical representation of u-tube geometry (left) and equivalent geometry (right)

A fully implicit scheme was programmed and solved using FORTRAN. The model is based on a standard finite volume discretization proposed by Patankar [19] and is solved using a GaussSeidel method. As can be seen from Figure 2 the model consists of concentric grout and soil cylinders. It should be noted that an additional volume of soil was incorporated underneath the borehole, which is also illustrated in Figure 2. The governing heat conduction equation, based on a $2 \mathrm{D}$ cylindrical coordinate system is restated here:

$$
\frac{1}{r} \cdot \frac{d}{d r} \cdot\left(k \cdot r \cdot \frac{d T}{d r}\right)+\frac{d}{d z}\left(k \cdot \frac{d T}{d z}\right)=\rho \cdot c_{p} \cdot \frac{d T}{d t}
$$

where $\mathrm{r}$ is the radial distance, $\mathrm{k}$ is thermal conductivity, $\mathrm{T}$ is temperature, $\mathrm{z}$ is the vertical distance, $\rho$ is density, $c_{p}$ is specific heat capacity, and $t$ is time.

For the finite volume discretization, an interior node is formulated as follows $[5,11]$ :

$$
-a_{n} \cdot T_{N}-a_{w} \cdot T_{W}+a_{p} \cdot T_{P}-a_{e} \cdot T_{E}-a_{s} \cdot T_{S}=b
$$

where,

$$
\begin{aligned}
& \mathrm{a}_{\mathrm{n}}=\frac{r e^{2}-r w^{2}}{2} \cdot \frac{k_{n}}{(d z)_{n}} \\
& \mathrm{a}_{\mathrm{w}}=r_{w} \cdot d z \cdot \frac{k_{w}}{(d r)_{w}}
\end{aligned}
$$




$$
\begin{aligned}
& \mathrm{a}_{\mathrm{p}}{ }^{0}=\rho \cdot c_{p} \cdot \frac{r e^{2}-r w^{2}}{2} \cdot \frac{d z}{d t} \\
& \mathrm{a}_{\mathrm{e}}=r_{e} \cdot d z \cdot \frac{k_{e}}{(d r)_{e}} \\
& \mathrm{a}_{\mathrm{s}}=\frac{r e^{2}-r w^{2}}{2} \cdot \frac{k_{s}}{(d z)_{s}} \\
& \mathrm{a}_{\mathrm{p}}=\mathrm{a}_{\mathrm{n}}+\mathrm{a}_{\mathrm{w}}+\mathrm{a}_{\mathrm{p}}{ }^{0}+\mathrm{a}_{\mathrm{e}}+\mathrm{a}_{\mathrm{s}} \\
& \mathrm{b}=a_{p}^{0} \cdot T_{p}^{0}
\end{aligned}
$$

and where re represents the distance from the centerline to the east interface of a control volume, rw is the distance from the centerline to the west interface, $\mathrm{dr}$ is the radial thickness of a control volume, $\mathrm{dz}$ is the vertical thickness of a control volume, $\mathrm{dt}$ is the time step.

The subscript 'p' relates to the center of a control volume and remaining subscripts 'n', 's', 'e', and 'w' refer to north, south, east and west interfaces, respectively. Superscript '0' is used to denote the notion of a previous value, which was true some ' $\mathrm{dt}$ ' time step before. The main notion behind Equation (7) is that it allows the physical domain which consists of concentric layers of grout and soil to be discretized into finite volumes. After control volume discretization is performed, Equations (8-13) are used to calculate the coefficients for the node of interest and the neighbouring nodes. This makes it possible to perform calculations in a matrix form with the coefficients and unknown temperature nodes on the left and known boundary conditions on the right. The computation is performed based on discretized time-steps. Equation (14) simply states that the previously known node temperature multiplied by $a_{p}^{0}$ can be used as a boundary condition for the interior node to solve for the present time node temperature. For instance, $T_{p}^{0}$ refers to the temperature of a control volume which is known ' $\mathrm{dt}$ ' time previously. All of the nodes in the fully implicit scheme are initially set to a temperature of $10^{\circ} \mathrm{C}$ in running actual simulations and through applying boundary conditions in the ' $b$ ' term of Equation (7) it becomes possible to solve the entire system through iterative manner. In verifying the numerical model against the analytical finite line-source solution, the grid was uniform for the purpose of achieving better accuracy. However, in experimental data validation and actual simulations, the 
grid was non-uniform with each consecutive node size being a multiple of that of the previous node. The non-uniform grid was required in order to reduce computational time. To ensure accuracy in experimental data validation and actual simulations, grid, time step and domain size independence were confirmed.

Essentially there are two types of standard boundary conditions applied; a constant temperature Dirichlet boundary and a given-heat flux Neumann boundary condition. The non-zero Neumann given-heat flux is calculated by dividing the rate of energy input from building demands by the interior area of the cylinder, and then considering system COP. The zero Neumann boundary condition is applied at the interior surface of the equivalent cylinder. It is applied at the interior surface through setting west and top gradients to zero for the nodes vertically adjacent to the interior surface and directly underneath the interior cylinder, respectively (see Figure 2).

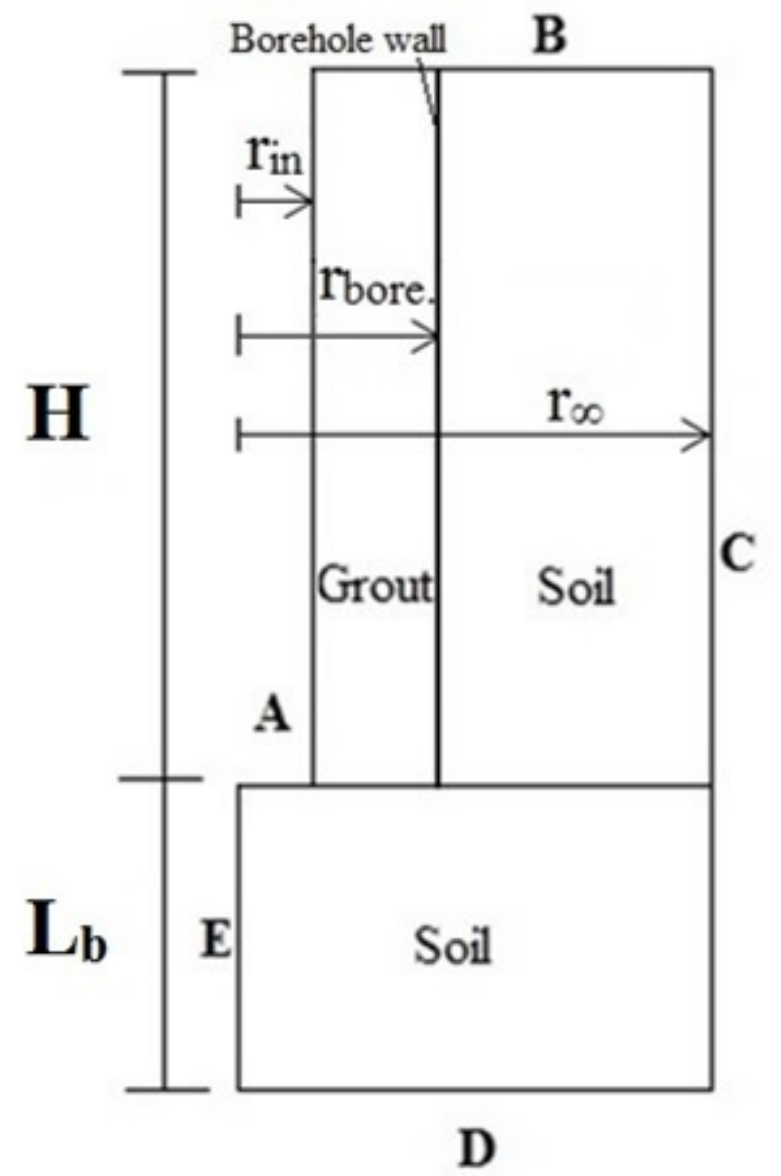

Figure 2. Graphical representation of 2D finite-volume model 


\subsection{Validation against the analytical finite line-source solution}

The analytical solution is based on the finite line-source model and is proposed in the following form [6]:

$$
T=T^{o}+\frac{q_{l}}{4 k \pi} \int_{0}^{H}\left\{\frac{\operatorname{erfc}\left(\frac{\sqrt{r^{2}+(z-h)^{2}}}{2 \sqrt{\alpha \tau}}\right)}{\sqrt{r^{2}+(z-h)^{2}}}-\frac{\operatorname{erfc}\left(\frac{\sqrt{r^{2}+(z+h)^{2}}}{2 \sqrt{\alpha \tau}}\right)}{\sqrt{r^{2}+(z+h)^{2}}}\right\} d h
$$

where $T^{o}$ is temperature at a previous time step, $q_{l}$ is heat transfer rate per unit length, $k$ is thermal conductivity, $H$ is the borehole depth, $r$ is radial distance, $z$ is vertical distance, $\alpha$ is thermal diffusivity, $\tau$ is time, $h$ is the integration constant.

The finite line-source model is transient and temperature is a function of radial distance and depth. However, it only allows for a single medium to be modelled. As such, in verifying the numerical 2D model against it, only the ground medium is modelled. Table 1 presents parameters used for comparison.

Table 1 - Parameters used in finite line-source validation

\begin{tabular}{|c|c|}
\hline Parameter & Value \\
\hline Borehole Height $(\mathrm{H})$ & $150 \mathrm{~m}$ \\
\hline Radial Soil Domain $\left(\mathrm{r}_{\infty}\right)$ & $4.34 \mathrm{~m}$ \\
\hline Underneath Soil Domain $\left(\mathrm{L}_{\mathrm{b}}\right)$ & $11.25 \mathrm{~m}$ \\
\hline Soil conductivity $\left(\mathrm{k}_{\text {soil }}\right)$ & $2.4 \mathrm{~W} \mathrm{~m}^{-1} \mathrm{~K}^{-1}$ \\
\hline Soil Density $\cdot$ Soil Specific Heat & $3.9 \times 10^{6} \mathrm{~J} \mathrm{~m}^{-3} \mathrm{~kg}^{-1}$ \\
\hline Heat transfer rate $\left(\mathrm{q}_{1}\right)$ & $100 \mathrm{~W} \mathrm{~m}^{-1}$ \\
\hline
\end{tabular}

Referring to Figure 2, to validate the numerical 2D model against the finite line-source solution, a constant heat flux of $1592 \mathrm{~W} / \mathrm{m}^{2}$ was applied as boundary condition A and instead of grout and ground layers, only one ground layer was incorporated into the numerical model. The constant 
heat flux of $1592 \mathrm{~W} / \mathrm{m}^{2}$ was calculated by dividing a constant heat transfer rate $\left(\mathrm{q}_{1}\right)$ of $100 \mathrm{~W} / \mathrm{m}$ by the perimeter of the interior cylinder, having a radius of $0.01 \mathrm{~m}$. The heat transfer rate of 100 $\mathrm{W} / \mathrm{m}$ was applied as the boundary condition $\left(\mathrm{q}_{1}\right)$ to the finite line-source model. In fact, it is possible to incorporate a transient heat transfer rate to the finite line-source solution by applying a series of different heat transfer rates at different time steps. However, the constant boundary condition was relied upon for validation purposes. Boundary condition B and bottom boundary condition D had constant temperatures of $0^{\circ} \mathrm{C}$ applied. The far field boundary condition $\mathrm{C}$ had a zero gradient applied. In turn, due to symmetry, boundary condition E had a zero gradient boundary condition applied as well.

In validating the numerical model against the finite line-source solution, the initial domain temperature was set to $0^{\circ} \mathrm{C}$. The temperature distribution for a depth of $75 \mathrm{~m}$ after 100 hours is presented in Figure 3. A time period of 100 hours was accepted because it gave a Fourier number of 2214, at interior surface of the ground cylinder, which was significantly greater than the criterion of 20 set by Ingersoll et al. [21]. The maximum relative percent error between the two models was determined to be $1.3 \%$ at the first node, located $10.5 \mathrm{~cm}$ away from the centerline. Due to the maximum relative percent error being quite small, the numerical model can be said to be successfully validated against the analytical finite line-source solution.

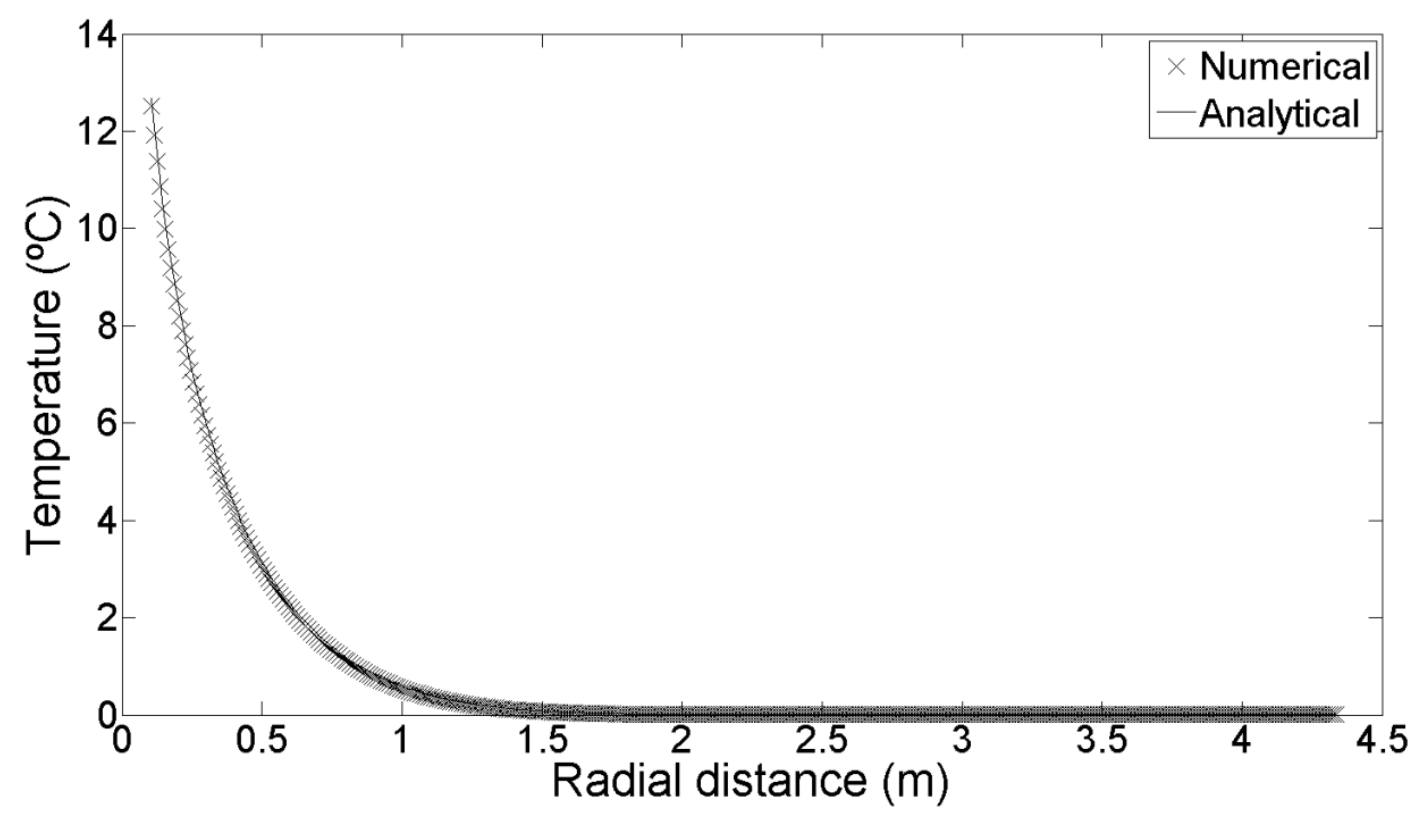

Figure 3. Comparison between numerical and analytical finite line-source model 


\subsection{Verification against experimental data}

Beier et al. [10] performed two experiments with a sand filled box to simulate operation of a vertical $u$-tube heat exchanger for other researchers to use the data in validating their models. The two tests included a constant heat input test and an interrupted heat input test. A large wooden square box was filled with sand and contained an aluminum pipe, which acted as the interface between the borehole grout and sand. The aluminum pipe with an inside radius of 6.3 $\mathrm{cm}$ contained high density polyethylene (HDPE) u-tube piping and was filled with bentonite grout. Each test monitored entering and exiting fluid temperature. In the present work, the mean of these two temperatures was applied as a constant temperature $\mathrm{BC}-\mathrm{A}$ in validating the numerical 2D model against experimental data in both cases. Parameters used are presented in Table 2.

Table 2 - Parameters used in experiment validation

\begin{tabular}{|c|c|}
\hline Parameter & Value \\
\hline Borehole Height $(\mathrm{H})$ & $18.3 \mathrm{~m}$ \\
\hline Radial Grout Domain $\left(\mathrm{r}_{\text {bore. }}\right)$ & $0.063 \mathrm{~m}$ \\
\hline Radial Soil Domain ( $\left.\mathrm{r}_{\infty}\right)$ & $37.5 \mathrm{~m}$ \\
\hline Underneath Soil Domain $\left(\mathrm{L}_{\mathrm{b}}\right)$ & $5.50 \mathrm{~m}$ \\
\hline Grout conductivity ( $\left.\mathrm{k}_{\text {grout }}\right)$ & $0.73 \mathrm{~W} \mathrm{~m}^{-1} \mathrm{~K}^{-1}$ \\
\hline Grout Density $\cdot$ Grout Specific Heat & $3.9 \times 10^{6} \mathrm{~J} \mathrm{~m}^{-3} \mathrm{~kg}^{-1}$ \\
\hline Soil conductivity $\left(\mathrm{k}_{\text {soil }}\right)$ & $2.82 \mathrm{~W} \mathrm{~m}^{-1} \mathrm{~K}^{-1}$ \\
\hline Soil Density $\cdot$ Soil Specific Heat & $2.9 \times 10^{6} \mathrm{~J} \mathrm{~m}^{-3} \mathrm{~kg}^{-1}$ \\
\hline
\end{tabular}

Figure 4 and 5 illustrate temperature results for 24,44 and $71.3 \mathrm{~cm}$ away from the borehole, at a depth of $6.41 \mathrm{~m}$, over a 52 hour experiment. The maximum relative percent error was determined 
to be 5.8 and $4.3 \%$ at $44 \mathrm{~cm}$ away from the borehole for the constant and interrupted heat input test, respectively. Due to the maximum relative percent errors for the two tests being relatively small, the model was said to be successfully validated once again.
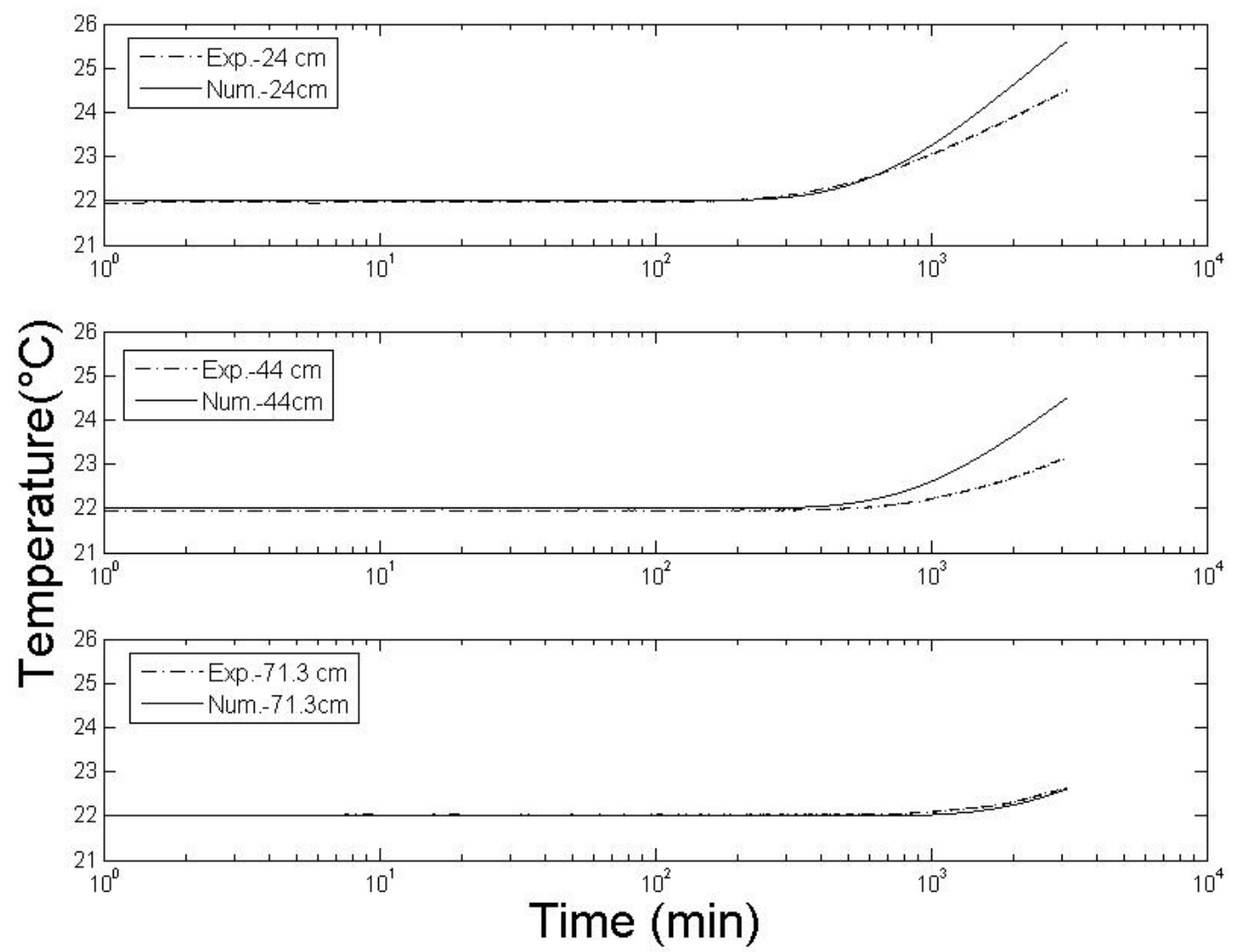

Figure 4. Validation of numerical model against experimental data [10] for the constant input test (Logarithmic scale was chosen for the purpose of clarity) 


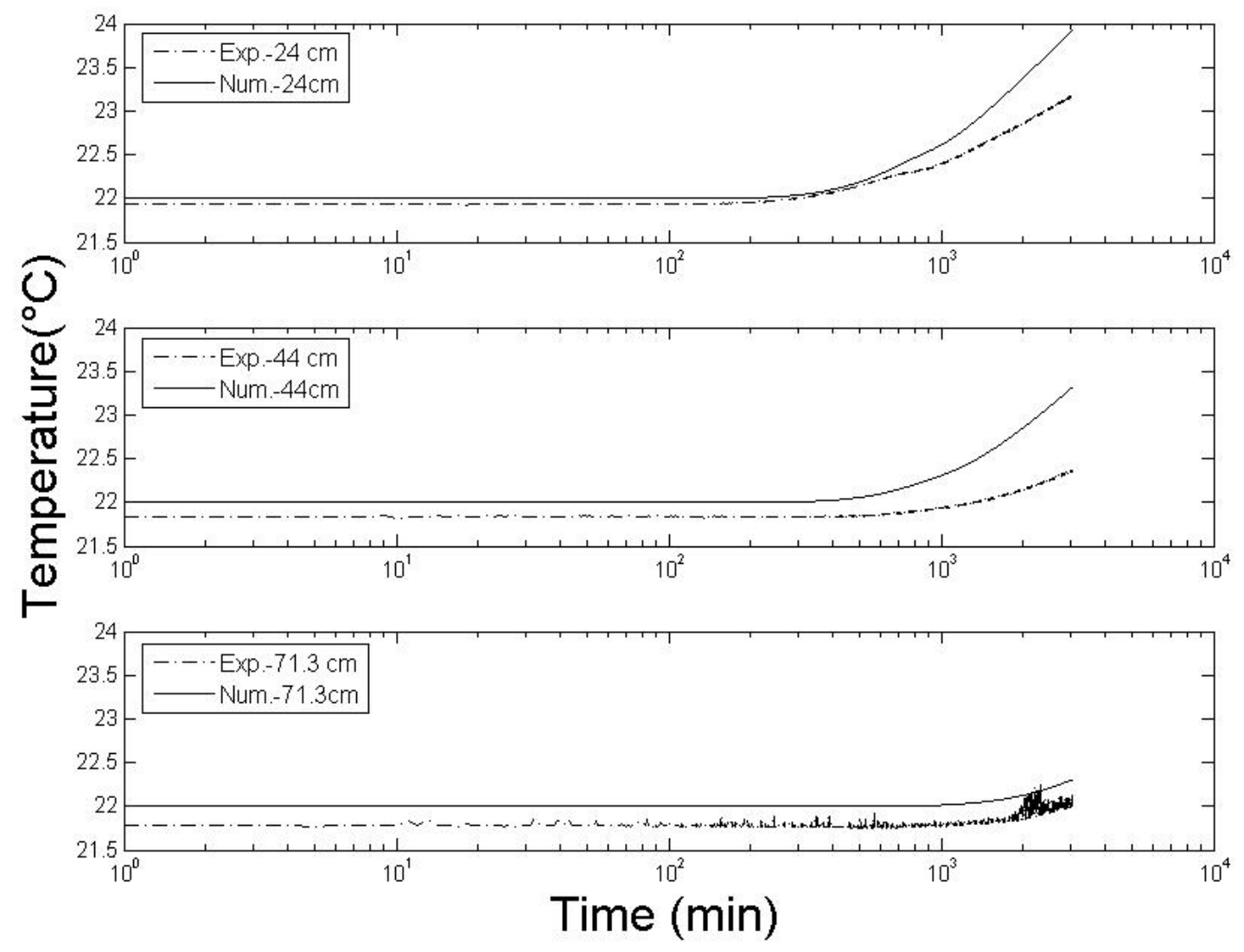

Figure 5. Validation of numerical model against experimental data [10] for the interrupted input test (Logarithmic scale was chosen for the purpose of clarity)

The logarithmic abscissa has been chosen for Figures (4) and (5) as the location of the thermocouples were $24 \mathrm{~cm}, 44 \mathrm{~cm}$ and $71.3 \mathrm{~cm}$ away from the energy source and therefore required about 5 hours to start rising in temperature. The logarithmic scale was chosen simply to present the results more clearly as there is no interesting response taking place within first five hours of the experiment.

\subsection{Temperature BC Algorithm}

Fortunately, the experiment in [10] reported entering and exiting water temperatures because the numerical model is designed to incorporate the most common temperatures at which ground coupled heat pumps operate through utilization of a temperature BC algorithm. Hence it was of interest to see if applying the mean temperature instead of a heat flux was realistic. Since the maximum errors when the numerical model was compared with the two tests were small, the 
assumption was accepted as sufficient. In order to bridge the gap between the energy demands of a building obtained from eQUEST [22] and the operating temperatures, it was necessary to design an algorithm that would relate the two.

The underlying principle behind the algorithm, which is illustrated in Figure 6, is based on three modes of operation: cooling, heating and off modes. Common operating temperatures for cooling and heating modes are $29.4^{\circ} \mathrm{C}\left(85^{\circ} \mathrm{F}\right)$ and $1.7^{\circ} \mathrm{C}\left(35^{\circ} \mathrm{F}\right)$, respectively [2]. Hence, during these two modes the respective temperatures are applied, and during the off mode, a zero gradient is applied as BC-A. The part of the algorithm surrounded by dashed lines (see Figure 6) is repeated for the number of years of interest; in this study it was twenty years.

Referring to Figure 6, the first step to transform building loads for a certain building into temperature BCs is to store 8760 annual cooling and heating loads from eQUEST [22] in two separate arrays. The second step involves applying cooling and heating COPs associated with operation of the heat pump. For instance, in this study, a constant COP of 3.5 was taken for both cooling and heating. As such, heat injected into the ground during cooling mode were based on initial cooling loads being increased by a factor of 1.4, and heat extracted in heating mode was equal to the initial heating loads multiplied by 0.71 . The factor of 1.4 is related to the additional heat produced by the heat pump in cooling mode having to be stored in the ground. Based on the definition of a heat pump cycle, dividing the COP by (COP-1) gives the factor of 1.4 for the cooling mode, since the ground is viewed as the 'hot' medium. It was assumed that all of the heat is stored in the ground. In heating mode, the factor of 0.71 is associated with the fact that less heat has to be taken out of the ground due to the energy of the heat pump work contributing towards meeting the building loads. The third step involves simply finding the peak cooling load and the peak heating load, which are the assumed designed rates at which the system operates in these two modes, out of 8760 cooling and heating loads. That is to say, the system uses single stage compressors of capacity equal to but not exceeding peak loads, with binary control.

The next part of the algorithm, surrounded by the dashed lines in Figure 6, has 8760 iterations which correspond to 8760 hours of a year. The counter ' $i$ ' is initially at zero and is updated by one each iteration at the fourth step. At the fifth step, the algorithm differentiates whether the system is in cooling, heating or no-load mode. The simplest out of the three is the no-load mode where a zero gradient is imposed as BC-A. The other two options, lead to an identical process 
and therefore it is sufficient to describe only one. If the code is faced with a cooling load in step five, it checks how much cooling in total has been supplied up until that moment in time. Initially, total cooling supplied and total cooling needed are set to zero. If total cooling supplied is greater than total cooling needed, in step six, the system needs to be turned off. Therefore, the actual load is added to total cooling needed and the algorithm stores the zero gradient to be applied as BC-A in step eight. Otherwise if total cooling needed is larger than total cooling supplied, in step seven, more cooling is needed than has been supplied. Hence, the system is turned on. Then one peak cooling load is added to total cooling supplied and $29.4^{\circ} \mathrm{C}$ is applied as BC-A in step nine. In step ten, the algorithm checks if the counter ' $i$ ' is less than or equal to 8760. If the counter ' $\mathrm{i}$ ' is greater than 8760 , it is set to one, and steps five to ten are repeated for another 8760 iterations. Otherwise, if the counter is less than or equal to 8760 , the algorithm returns to step four. 


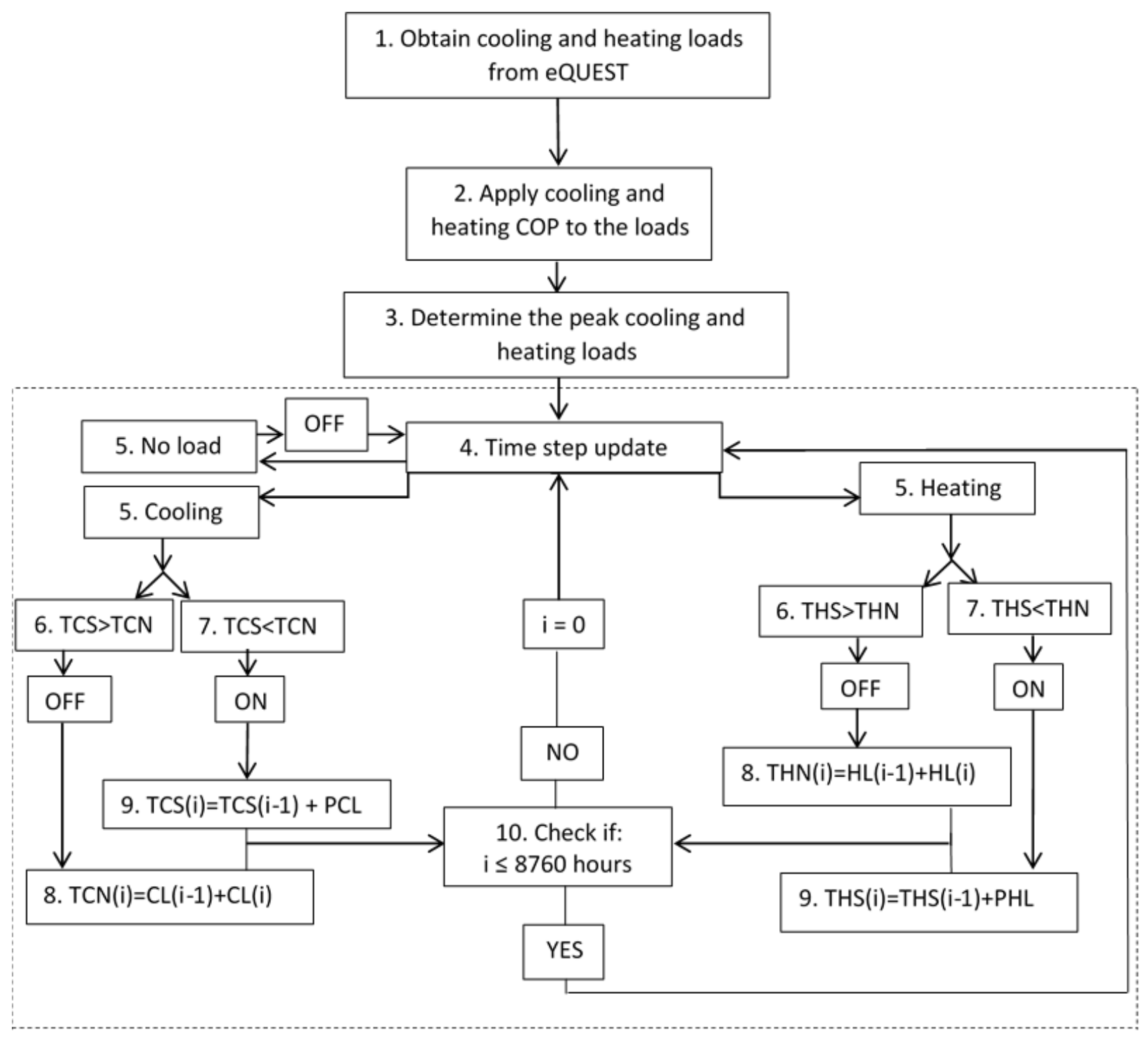

Figure 6. Temperature BC algorithm

In fact, there will be a minor error associated with applying a uniform temperature as $\mathrm{BC}-\mathrm{A}$, for cooling and heating modes, since temperature varies across the u-tube and may slightly fluctuate as the system is initially turned on. Nevertheless, since the goal of the paper is to examine long term fouling effects, the associated error is of an irrelevantly small timescale.

It is important to note that mean monthly temperatures were calculated for the year 2013 based on values provided in [20] and were applied for each hour, for all twenty years as BC-B. 


\section{Results and Discussion}

Through obtaining hourly cooling and heating loads from eQUEST [22] it was possible to use the temperature $\mathrm{BC}$ algorithm to determine hourly $\mathrm{BC}-\mathrm{A}$ values over twenty years for each of the buildings. As the 2D finite volume model provides insight into long-term temperature response of the ground, performance of the hybrid and non-hybrid system in terms of temperature rise can be compared. Through quantifying temperature rises in each of the systems, it becomes possible to determine the level of fouling reduction which is achievable through hybridization. There were twelve buildings ( $a-1)$ out of which eight were cooling dominant and four were heating dominant. The level of hybridization for the twelve buildings spanned from nearly zero to 0.93 in order to provide a sufficient range to give insight into the effect of hybridization on fouling reduction. The first four buildings $(\mathrm{a}-\mathrm{d})$ which were a school (a), transit facility (b), mid-rise (c) and high-rise building (d) will be described in detail and more concise results will be presented for the other eight buildings $(\mathrm{e}-1)$.

The building with the largest shave factor $(\alpha)$ of 0.84 , out of the first four buildings $(a-d)$, was the school (Figure 7). The school is located in Orillia, Canada and has two floors. A transit facility had the second highest shave factor of 0.82 . It has one floor and is loosely based on a building in the Toronto, Canada area. The multifamily, mid-rise building has six floors. It is located in Milton, Canada and had a shave factor of 0.74. Lastly, the high-rise has five floors and is in Hamilton, Canada with a shave factor of 0.27. All buildings were cooling dominant except the high-rise. The reason for choosing the majority of buildings to be cooling dominant for analysis is due to the fact that ground overheating is a much more frequent problem than overcooling in geo-exchange technologies. It should be mentioned that the value of a shave factor is strongly influenced by economic parameters such as electricity and gas costs. The more cooling dominant a building is, the more profitable it is to install a GSHP and consequently have a large shave factor. For instance, the school was much more cooling dominant than the high-rise and therefore had a shave factor of 0.84 and not 0.27 . The results for a ground temperature as a function of operation life for the school, transit facility, mid-rise and high-rise are illustrated in Figure 7. 

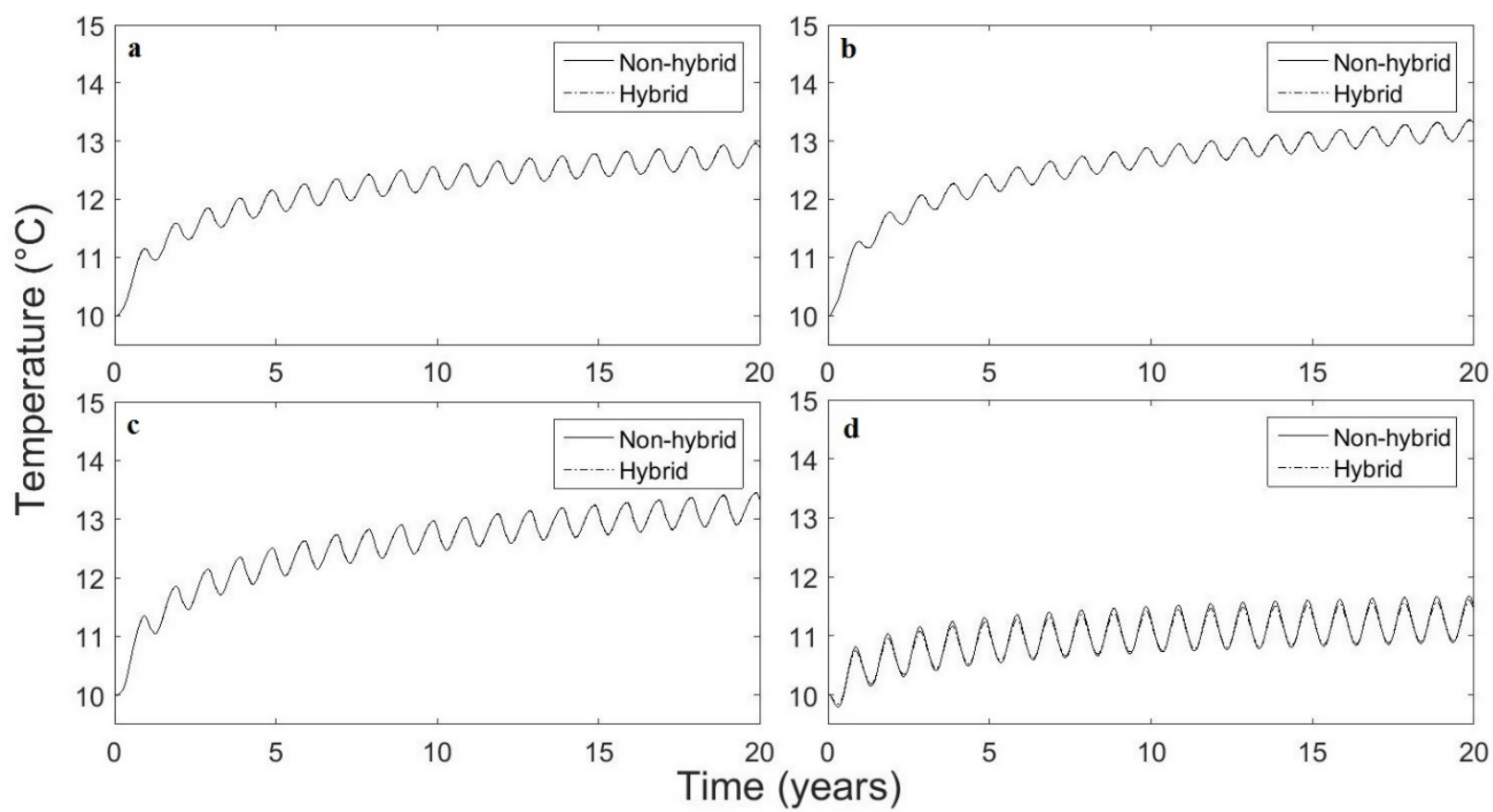

Figure 7. Ground temperature profile for 20 years of operation of the school (a), transit facility (b), mid-rise (c) and high-rise (d)

As can be seen from the presented results, average annual ground temperature significantly increases within the first five years of operation for all four systems and then slowly plateaus with time. For the first three buildings, temperature increased by approximately $3^{\circ} \mathrm{C}$ over the entire operation period of twenty years. Results for the first three buildings $(a-c)$ demonstrated that there is no significant difference between hybrid and non-hybrid system operation as far as ground temperature is concerned since the two temperature profiles overlap. It should be noted that for these three buildings, the shave factor was between 0.74 and 0.84 . Therefore, the bulk of the heating and cooling is supplied by the geo-exchange system. On the other hand, results for the high-rise demonstrated about $1.5^{\circ} \mathrm{C}$ ground temperature increase over twenty years in the non-hybrid case and $1.4^{\circ} \mathrm{C}$ rise in the hybrid case. The shave factor in this case was only 0.27 and would lead one to expect that the difference between the hybrid and non-hybrid systems would be much more noticeable. An intuitive hypothesis that the hybrid system will have a much smaller ground temperature rise on the basis of a small shave factor is proven as wrong through the obtained results. The crucial factor which influences temperature rise in that case must be the amount of total cooling demand which is met by the GSHP. For instance, the first two buildings had $99.2 \%$ of the total cooling demand met, and the third and fourth building had $98.7 \%$ and 
$80.4 \%$ of total cooling demand met, respectively. Hence, the reason why the temperature profiles presented in Figure 7 look almost identical for all four buildings is due to a large percentage of the total cooling demands being met by the hybrid GSHP systems.

The calculations were repeated for eight additional buildings and the results are presented in Figures 8 and 9 . Table 3 presents the level of hybridization in terms of shave factors, total cooling demand met, total heating demand met, percent fouling reduction and temperature rise after twenty years in hybrid and non-hybrid cases for all buildings. Shave factors have two categories: cooling dominant shave factors are given the symbol $(\alpha)$ and heating dominant shave factors are given the symbol $(\beta)$. All of the eight cooling dominant buildings which had large shave factors varying from 0.66 to 0.93 experienced extremely low fouling reduction, nearly $0 \%$. The same trend as with the four buildings $(a-d)$ presented in Figure 7 is observed in Figures 8 and 9 for the eight additional buildings $(\mathrm{e}-1)$. The reason that hybrid systems are hardly distinguishable from the non-hybrid systems is again most likely due to large total cooling demands being met by the GSHP. The smallest percentage of the total cooling demand met by the GSHP was in the case of building $\mathrm{i}$ (out of the eight cooling dominant buildings) with $97.9 \%$. This is consistent with the results obtained for the first four buildings as the percentage is within $95 \%$ to unity range and is therefore expected that the fouling reduction will be nearly $0 \%$. Building $i$ with the smallest shave factor of 0.66 experienced $0 \%$ fouling due to its total cooling portion met being very large (97.9\%). The range within which the effect of hybridization on fouling reduction becomes more noticeable is within the low 80 s (\%) margin as illustrated by the high-rise building $\mathrm{d}$ from Figure 7 and buildings $\mathrm{j}$, $\mathrm{k}$ and 1 from Figure 9. A factor in preventing fouling reduction for heating dominant buildings is the percentage of the total cooling demand met by the GSHP. 

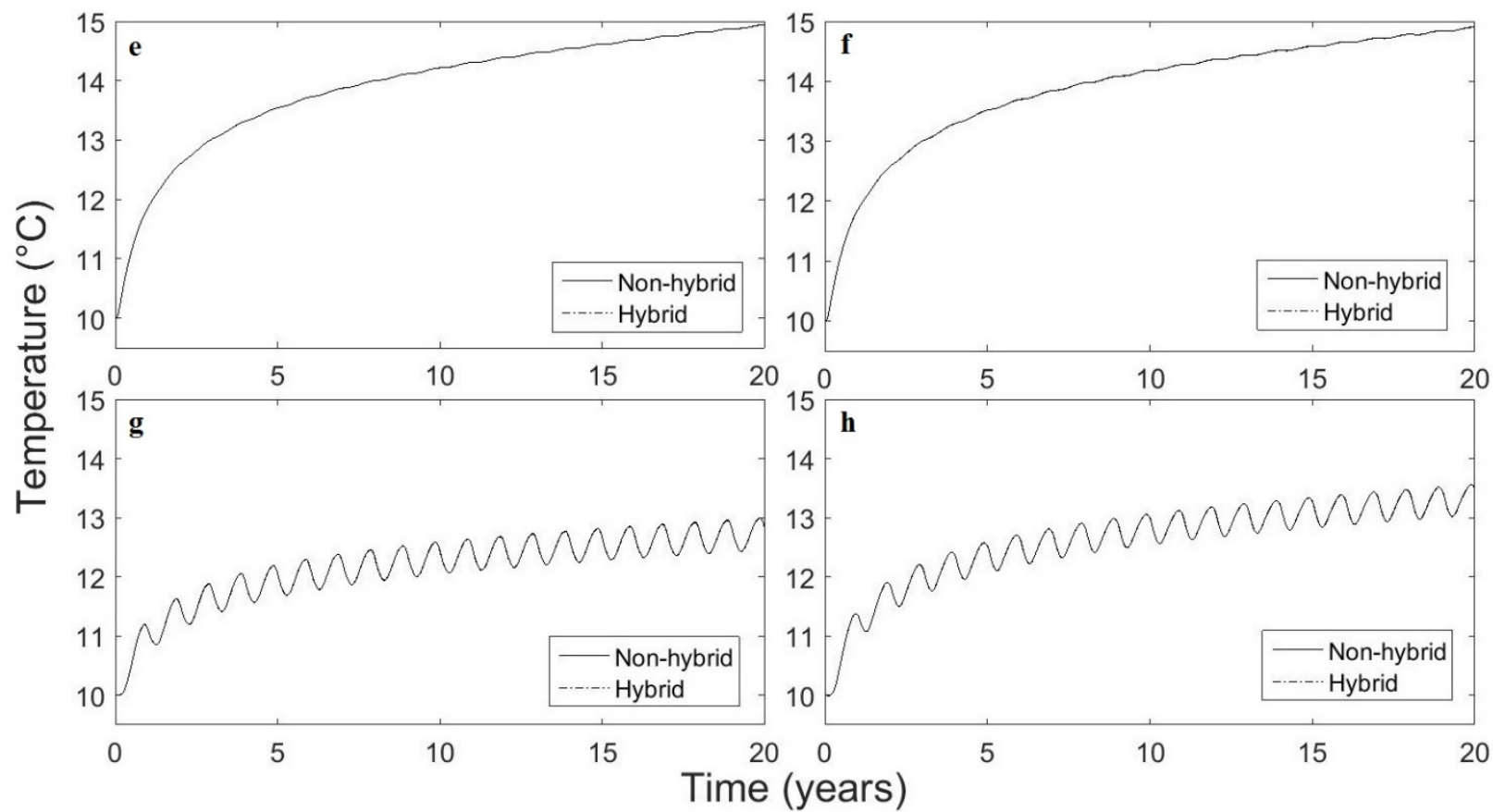

Figure 8 - Ground temperature profile for 20 years of operation of buildings e, $\mathrm{f}, \mathrm{g}$ and $\mathrm{h}$

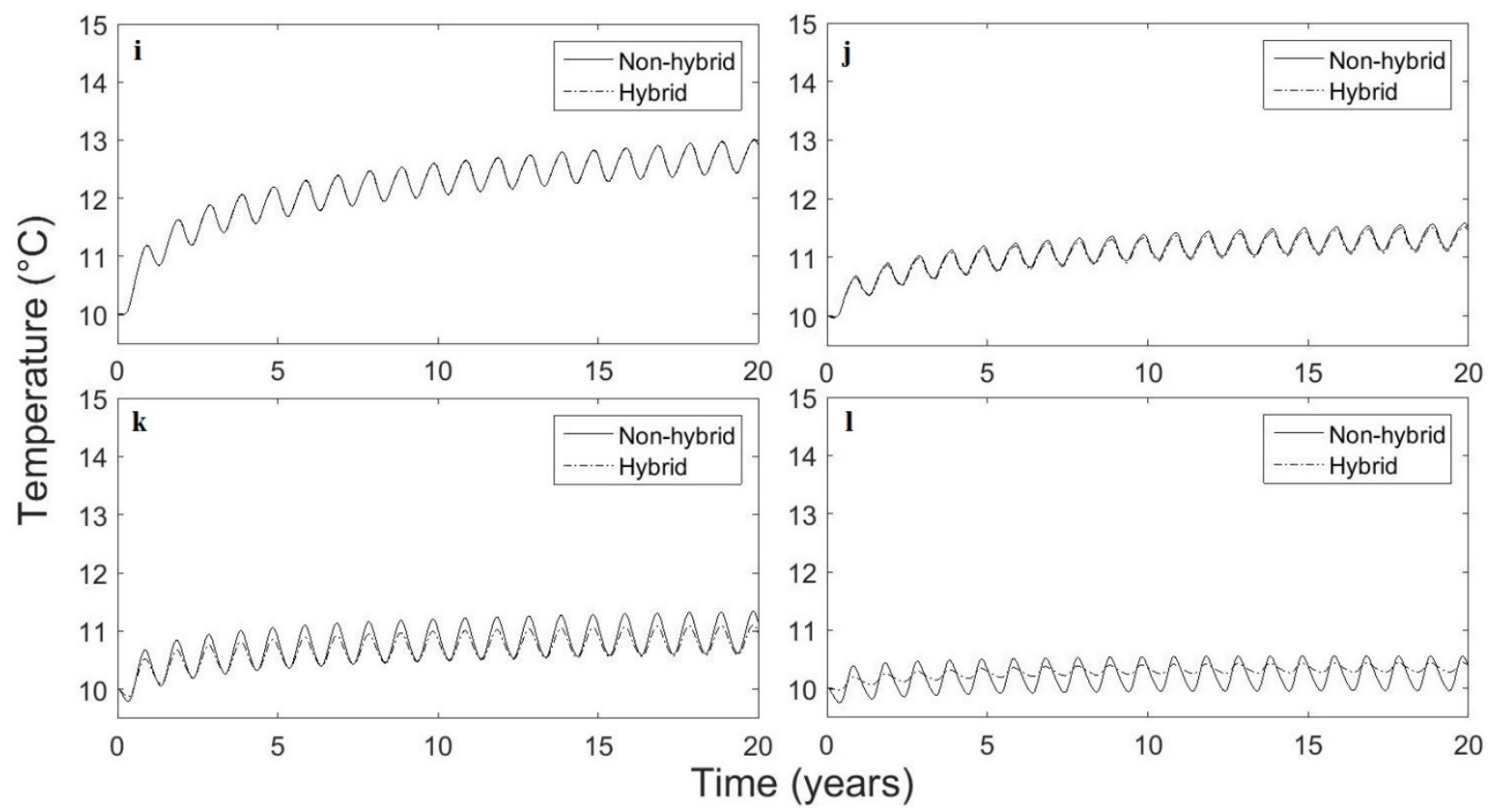

Figure 9 - Ground temperature profile for 20 years of operation of buildings $i, j, k$ and 1

Even all heating dominant buildings experienced ground overheating. This result is due to heat pumps producing extra heat in cooling mode and having to take less heat out of the ground in the 
heating mode. Fouling reduction was the highest in the case of building k (1.8\%). Although, the system can be said to be highly hybridized because of its small shave factor of 0.21 , its total cooling demand met was still significant (60.7\%) and in fact was higher than its total heating demand met $(51.5 \%)$. This result further serves in the favour of the conclusion presented by previous results as the percentage of the total cooling demand is not only much more influential than the shave factor but also more influential than the total heating demand met.

Further analysis reveals that a smaller percentage of total cooling demand met for building 1 $(40.7 \%)$ than building $\mathrm{k}(60.7 \%)$ resulted in a much more balanced ground energy storage. It is true that building 1's hybrid system is hardly distinguishable from the non-hybrid system in terms of fouling reduction but the temperature rise after twenty years of operation is less severe $\left(0.4^{\circ} \mathrm{C}\right)$ than that in the case of building $\mathrm{k}\left(1.0^{\circ} \mathrm{C}\right)$. In addition, besides improving the energy storage, hybridization may also lessen the ground temperature rise during peak load seasons. It can be observed from Figure 9 that although fouling reduction after twenty years is nearly zero for building 1, its hybrid system does alleviate temperature rise during peak season. One benefit of having the smaller ground temperature rise during peak seasons is a higher COP of the system and ultimately a smaller amount of electricity consumption. 
Table 3 - Summary of Results

\begin{tabular}{|l|c|c|c|c|c|c|c|}
\hline & $\begin{array}{c}\mathrm{CD} / \\
\mathrm{HD}\end{array}$ & $\begin{array}{c}\text { Shave factor, } \\
\alpha(\beta)\end{array}$ & $\begin{array}{c}\text { TCDM } \\
(\%)\end{array}$ & $\begin{array}{c}\text { THDM } \\
(\%)\end{array}$ & $\begin{array}{c}\text { Percent } \\
\text { fouling } \\
\text { red. }(\%)\end{array}$ & $\begin{array}{c}\text { Temp. Rise } \\
(\text { Non-hybrid }) \\
\left({ }^{\circ} \mathrm{C}\right)\end{array}$ & $\begin{array}{c}\text { Temp. Rise } \\
(\text { Hybrid }) \\
\left({ }^{\circ} \mathrm{C}\right)\end{array}$ \\
\hline School (a) & $\mathrm{CD}$ & $0.84(1)$ & 99.2 & 100 & 0.0 & 2.9 & 2.9 \\
\hline $\begin{array}{l}\text { Transit } \\
\text { facility (b) }\end{array}$ & $\mathrm{CD}$ & $0.82(1)$ & 99.2 & 100 & 0.0 & 3.3 & 3.3 \\
\hline $\begin{array}{l}\text { Mid-rise } \\
\text { building (c) }\end{array}$ & $\mathrm{CD}$ & $0.74(1)$ & 98.7 & 100 & 0.0 & 3.3 & 3.3 \\
\hline $\begin{array}{l}\text { High-rise } \\
\text { building (d) }\end{array}$ & HD & $0.27(0.27)$ & 80.4 & 64.6 & 0.9 & 1.5 & 1.4 \\
\hline Building e & $\mathrm{CD}$ & $0.93(1)$ & 100 & 100 & 0.0 & 4.9 & 4.9 \\
\hline Building f & $\mathrm{CD}$ & $0.88(1)$ & 99.6 & 100 & 0.0 & 4.9 & 4.9 \\
\hline Building g & $\mathrm{CD}$ & $0.74(1)$ & 98.5 & 100 & 0.8 & 2.9 & 2.8 \\
\hline Building h & $\mathrm{CD}$ & $0.72(1)$ & 98.7 & 100 & 0.0 & 3.5 & 3.5 \\
\hline Building $\mathrm{i}$ & $\mathrm{CD}$ & $0.66(1)$ & 97.9 & 100 & 0.0 & 2.9 & 2.9 \\
\hline Building j & HD & $0.44(0.44)$ & 88.4 & 85.1 & 0.9 & 1.5 & 1.4 \\
\hline Building k & HD & $0.21(0.21)$ & 60.7 & 51.5 & 1.8 & 1.2 & 1.0 \\
\hline Building 1 & HD & $0.02(0.02)$ & 40.7 & 7.84 & 0.0 & 0.4 & 0.4 \\
\hline
\end{tabular}

The twelve cases presented in Table 3 are based on analysis of actual buildings which had GSHPs installed. Building dimensions and occupancy patterns were obtained from industrial collaborators and energy consumptions were modelled in eQUEST [22] building energy simulations as part of potential installation evaluation. The sample of buildings is a good cross section of various systems which exist on the marketplace as it contains shave factors spanning from 0.02 to 0.93 and buildings which are both cooling and heating dominant.

Ground temperature rises as high as $4.9^{\circ} \mathrm{C}$ are associated with some of the buildings, with hybridization having little effect. As the level of hybridization determined by the shave factor 
was proven to have negligible influence on alleviation of energy storage imbalance, it was necessary to investigate parameters that do strongly affect it. Based on the previously discussed results, one strong parameter which induces ground fouling was noticed to be the percentage of total energy demand met. Hence, it was of interest to further investigate relationship between the temperature rise in hybrid systems and the difference between total heating and total cooling demand met as well as the portion of total energy demand met by the GSHP system. The left part of Figure 10 plots the temperature rise inside the hybrid systems for all twelve buildings against the absolute difference between total heating and total cooling demand met and the right part of the figure plots ground temperature rise versus total energy demand met.
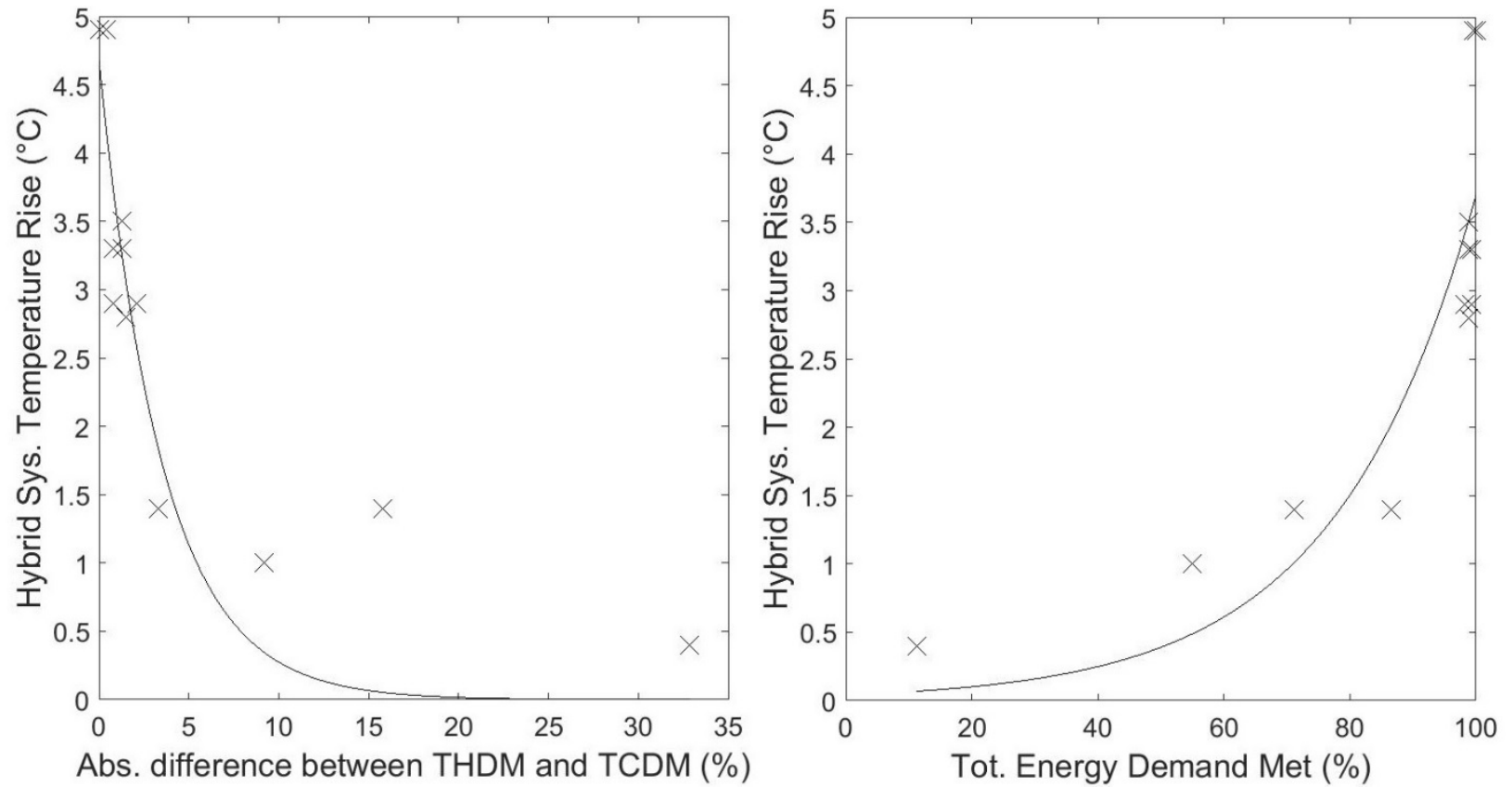

Figure 10 - Influential parameters on fouling reduction

Based on Figure 10, it can be said that ground temperature rise decreases as the difference between total heating and total cooling demand increases and increases as total energy demand met by the system increases. Small differences between total heating and total cooling demand met implies that the building loads prior to taking the effects of the heat pump into account are nearly equal, and that the building is better suited towards a balanced system. The role of COP in amplifying the effect of cooling which leads to overheating in both cooling and heating dominant systems should also be noted. Therefore, if a system is to be properly balanced, more of building's total heating than total cooling demands need to be met by the GSHP system in order 
to balance out the effects of COP. Based on the same logic, it is usually the case that the more total energy demand the GSHP meets, the more cooling it will have to supply over the years, which based on the observed trend in Figure 10 results in ground fouling.

\section{Conclusions}

The paper has presented a finite volume 2D heat transfer model, consisting of concentric grout and ground layers, which was representative of actual ground coupled heat pump systems possessing complex u-tube geometries. The assumptions of a constant COP of 3.5 as well as a constant operating temperature for heating and cooling modes were made. In fact, these two assumptions will act as the main sources of error. Furthermore, the model was successfully validated against an analytical finite line-source solution and experimental data in [10] with the maximum error of $1.3 \%$ and $5.8 \%$, respectively.

The model can be used in GSHP design to effectively model long-term heat transfer in single borehole systems and also compare operation of GSHPs with different degrees of hybridization for the purposes of improving the quality of GSHP designs.

This paper has compared hybrid and non-hybrid systems for various building types. Systems need to be significantly hybridized in order to start seeing slight reduction in ground fouling. The largest ground fouling reduction of $1.8 \%$ was achieved in the building $\mathrm{k}$ case with a shave factor of 0.21. Overall, hybridization has been proven to be an ineffective method of reducing ground fouling. The reason being that even in highly hybridized systems, large portions of the cooling demands can still be met by the GSHP and ultimately lead to unsustainable rises in ground temperature.

\section{Acknowledgements}

The authors would like to acknowledge financial support from The Natural Sciences and Engineering Research Council of Canada (NSERC). 


\section{References}

[1] D. Paré, "Comparative Analysis of Greenhouse Gas Emissions of Various Residential Heating Systems,” April, 2010.

[2] M. Alavy, H. V. Nguyen, W. H. Leong, and S. B. Dworkin, “A methodology and computerized approach for optimizing hybrid ground source heat pump system design," Renew. Energy, vol. 57, pp. 404-412, 2013.

[3] T. Kurevija, D. Vulin, and V. Krapec, "Effect of borehole array geometry and thermal interferences on geothermal heat pump system," Energy Convers. Manag., vol. 60, pp. 134-142, 2012.

[4] S. Koohi-Fayegh and M. a. Rosen, "An analytical approach to evaluating the effect of thermal interaction of geothermal heat exchangers on ground heat pump efficiency," Energy Convers. Manag., vol. 78, pp. 184-192, 2014.

[5] A. Salimshirazi, UNIVERSITÉ DE MONTRÉAL TRANSIENT HEAT TRANSFER IN VERTICAL GROUND HEAT EXCHANGERS ALI SALIMSHIRAZI ÉCOLE POLYTECHNIQUE DE MONTRÉAL THĖSE PRÉSENTÉE EN VUE DE L ' OBTENTION DU DIPLÔME DE PHILOSOPHIAE DOCTOR ( GÉNIE MÉCANIQUE ) JUILLET 2012. 2012.

[6] H. Y. Zeng, N. R. Diao, and Z. H. Fang, “A finite line-source model for boreholes in geothermal heat exchangers," Heat Transf. - Asian Res., vol. 31, no. 7, pp. 558-567, 2002.

[7] Zeng HY, Diao NR, Fang Z, "Heat transfer analysis of boreholes in vertical ground heat exchangers," Int J Heat Mass Transf. 2003; 46(23):4467-81.

[8] G.-H. Go, S.-R. Lee, S. Yoon, H. Park, and Sk. Park, "Estimation and experimental validation of borehole thermal resistance,” KSCE J. Civ. Eng., vol. 18, no. 4, pp. 992-1000, 2014.

[9] J. a Shonder and J. Beck V., "Field Test of a New Method for Determining Soil Formation Thermal Conductivity and Borehole Resistance," ASHRAE Trans., vol. 106, no. 1, pp. 1-8, 2000. 
[10] R. a. Beier, M. D. Smith, and J. D. Spitler, "Reference data sets for vertical borehole ground heat exchanger models and thermal response test analysis," Geothermics, vol. 40, no. 1, pp. 79$85,2011$.

[11] P. Bayer, M. de Paly, and M. Beck, "Strategic optimization of borehole heat exchanger field for seasonal geothermal heating and cooling," Appl. Energy, vol. 136, pp. 445-453, 2014.

[12] W. Retkowski, G. Ziefle, and J. Thöming, "Evaluation of different heat extraction strategies for shallow vertical ground-source heat pump systems," Appl. Energy, vol. 149, pp. 259-271, 2015.

[13] W. Retkowski and J. Thöming, "Thermoeconomic optimization of vertical ground-source heat pump systems through nonlinear integer programming," Appl. Energy, vol. 114, pp. 492$503,2014$.

[14] Y. Shang, M. Dong, and S. Li, "Intermittent experimental study of a vertical ground source heat pump system,” Appl. Energy, vol. 136, pp. 628-635, 2014.

[15] Esen, H., Esen, M., \& Ozsolak, O. (2015). Modelling and experimental performance analysis of solar-assisted ground source heat pump system. Journal of Experimental \& Theoretical Artificial Intelligence, 3079 (November), 1-17. http://doi.org/10.1080/0952813X.2015.1056242

[16] Balbay, A., \& Esen, M. (2013). Temperature distributions in pavement and bridge slabs heated by using vertical ground-source heat pump systems - doi: 10.4025/actascitechnol.v35i4.15712. Acta Scientiarum. Technology, 35, 677-685. http://doi.org/10.4025/actascitechnol.v35i4.15712

[17] Balbay, A., \& Esen, M. (2010). Experimental investigation of using ground source heat pump system for snow melting on pavements and bridge decks. Scientific Research and Essays, 5(24), 3955-3966.

[18] Esen, M., \& Yuksel, T. (2013). Experimental evaluation of using various renewable energy sources for heating a greenhouse. Energy and Buildings, 65, 340-351.

http://doi.org/10.1016/j.enbuild.2013.06.018

[19] S. Patankar, "Numerical heat transfer and fluid flow," Series in computational methods in mechanics and thermal sciences. pp. 1-197, 1980.

[20] "Monthly Data Report for 2013" Government of Canada, Toronto. Web. 
http://climate.weather.gc.ca/climateData/monthlydata_e.html?timeframe $=3 \& \operatorname{Prov}=\&$ StationID $=$ 4841\&mlyRange $=1986-01-01 \mid 2013-12-01 \&$ Year=2013\&Month=7\&Day=26

[21] Ingersoll, L. R., Zobel, O. J., Ingersoll, A. C. "Heat conduction with engineering geological and other applications," New York: McGraw-Hill, ed. 2, 1954.

[22] eQUEST. Retrieved June, 2014, from: DOE2.com: http://doe2.com/equest/. 